\title{
REVIEW
}

\section{Cystic fibrosis related diabetes}

Liviu-Laurențiu Pop ${ }^{1,2}$, Mihaela Dediu ${ }^{1}$, Iulian Velea ${ }^{1}$, Mirela Mogoi ${ }^{1}$, Ioana M. Ciuca ${ }^{1,2}$

${ }^{1}$ University of Medicine and Pharmacy "Victor Babes", Pediatric Department, Timisoara

${ }^{2}$ National Cystic Fibrosis Centre, Timisoara, Romania

\section{Correspondence to:}

Mihaela Dediu, University of Medicine and Pharmacy "Victor Babes", Pediatric Department, Evlia Celebi 1-3, 300 226, Timisoara, Romania

E-mail: mihaela.dediu@gmail.com

\section{Conflicts of interests}

Nothing to declare

\section{Acknowledgements}

None

Funding: This research did not receive any specific grant from funding agencies in the public, commercial or not-for profit sectors.

Keywords: cystic fibrosis, related diabetes, childhood.

These authors take responsibility for all aspects of the reliability and freedom from bias of the data presented and their discussed interpretation.

Central Eur J Clin Res 2019;2(1):23-27

Received: 02.02.2019, Accepted: 27.02.2019, Published: 18.03.2019

Copyright $\odot 2018$ Central European Journal of Clinical Research. This is an open-access article distributed under the Creative Commons Attribution License, which permits unrestricted use, distribution, and reproduction in any medium, provided the original work is properly cited.

\section{Abstract}

Cystic fibrosis related diabetes (CFRD) is a redoubtable complication associated to cystic fibrosis, with an increasing frequency, directly proportional to children life expectancy. Although this complication has similar features with DM type 1 and some with type 2, the evolution and even the response to insulin therapy is different. It is also possible that other factors to influence the CFRD clinical expression and subsequently the disease evolution. Since its $1 \mathrm{t}$ diagnosis was associated with more frequent pulmonary exacerbations and with the deterioration of the respiratory status, therefore CFRD must be early and correctly diagnosed and managed. The aim of this paper is to present an overview of the recent updates and recommendations regarding this important CF complication.

\section{Introduction}

Cystic Fibrosis Related Diabetes (CFRD) is an important complication associated to cystic fibrosis, with an increased frequency directly proportional to these children life expectancy. Although this complication presents similarity to Diabetes mellitus type 1 and type 2 with different trends and response to insulin therapy. It is possible that other factors influence the clinical expression of CFRD and its development. Right from the beginning CFRD is associated with an increase in the frequency of pulmonary exacerbations associated to respiratory damage status. So, it is important to 
diagnose and set up an early and correct treatment. The purpose of this scientific paper is to present an overview of the latest updates and recommendations regarding this cystic fibrosis (CF) important complication.

Cystic fibrosis, the most common monogenic disease with recessive autosomal recessive transmission among Caucasian population, is a potentially fatal illness, characterized clinically by an impressive polymorphism. The recent epidemiology data describes a decreasing trend of this disease incidence rate having an average calculated incidence on European level of 1:3500 [1]. The recent data describes in our country an incidence of 1:2056 [2]. The cause of this disease is a mutation in the CFTR gene (the cystic fibrosis transmembrane conductance regulator gene), which encodes a chloride channel, with a role in adjusting the transport of water and $\mathrm{Na}$ though the cell membrane [3].

As the patient's age increase, complications such as diabetes occur in addition to the existing CF pathology. CFRD is frequently associated to chronic hepatopathy +/-secondary cirrhosis [4] and osteopathy, secondary liposoluble vitamins deficiency and their increased consumption [5]. Cystic Fibrosis Related Diabetes (CFRD) is the most frequent comorbidity of CF patients and represents a distinct form of diabetes, which includes similar characteristics to both type 1 and type 2 Diabetes. The average diagnosis age is between 18-20 years old [6].

As the disease progresses, destruction of exocrine pancreatic tissue accompanied by pancreatic beta-cells impairment with decreased insulin secretion.

The defective CFTR mRNA leads to a mutation to the nature of secretion making it viscous which eventually lead to obstructive lesions. The significantly low insulin secretion may explain why CFRD patients never develop ketosis. This peculiarity may be explained by the low glucagon secretion during hypoglycemia [7].

In non- diabetes CF patients, the insulin sensitivity is often normal. However, there are many factors that can influence this sensitivity as: glucocorticoids, parenteral nutrition, pregnancy, pulmonary exacerbations and hepatopathy.

\section{Clinical manifestations}

CFRD has a slow, insidious onset and patients can be asymptomatic for a long period of time. Most of the times the CFRD manifests when insulin resistance is increased during infectious lung exacerbations or throughout the corticotherapy periods.
Table 1. Clinical symptoms in CFRD [8]

\begin{tabular}{|l|}
\hline Polyuria or Polydipsia \\
\hline $\begin{array}{l}\text { Failure to gain/mantain weight, despite } \\
\text { nutritional interventions }\end{array}$ \\
\hline Poor growth rate \\
\hline Delayed puberty \\
\hline Decline in pulmonary functions \\
\hline Absence of clinical symptoms \\
\hline
\end{tabular}

\section{Diagnosis}

Early identification at onset with the establishment of specific CFRD treatment has a positive impact on the patient's health. In order to prevent deterioration of lung function and nutritional status it is mandatory to have an annual screening for diabetes after 10 years of age [9]. In addition, the patients showing a significant unexplained weight loss, despite a balanced appetite and an appropriate caloric intake, as well as those with non-responsive treatment lung exacerbations, have to be checked also.

Oral glucose challenge test (OGTT) is considered the gold standard in the diagnosis of cystic fibrosis related diabetes [10]. OGTT is carried out within the framework of periodic routine control, apart from the lung exacerbation periods or during glucocorticoid therapy.

Table 2. OGTT Interpretation [11]

\begin{tabular}{|c|c|}
\hline $\begin{array}{c}\text { Normal } \\
\text { OGTT }\end{array}$ & Repeat OGTT after 1 year \\
\hline $\begin{array}{c}\text { Impaired } \\
\text { glucose } \\
\text { tolerance }\end{array}$ & $\begin{array}{c}\text { Repeat OGTT after 1 year or } \\
\text { earlier if the clinical status of } \\
\text { patient is altered (attention to } \\
\text { symptomatology) }\end{array}$ \\
\hline $\begin{array}{c}\text { CFRD in an } \\
\text { asymptomatic } \\
\text { patient }\end{array}$ & $\begin{array}{c}\text { daily glycemic profile for } 2 \\
\text { weeks with a proper dietary } \\
\text { regimen; if the profile is } \\
\text { normal, the OGTT will be } \\
\text { repeated within 6 months }\end{array}$ \\
\hline
\end{tabular}

The CFRD onset is considered the moment when the CF patients meet the diagnostic criteria even if the blood glucose level subsequently returns to normal. According to the 2014 ISPAD (based on ADA 2010 criteria), a cystic fibrosis patient may be diagnosed with diabetes if he meets one of the following criteria [8]:

1. Patient with a stable clinical CF, the diagnosis of CFRD can be determined on the basis of the following criteria:

- fasting blood glucose $\geq 126 \mathrm{mg} \%$, or

- OGTT: 2 h glucose $\geq 200 \mathrm{mg} \%$, or $\mathrm{HbA} 1 \mathrm{c} \geq 6.5 \%$ (a lower value does not exclude 
the diagnosis) or glycemia level at any time of the day $\geq 200 \mathrm{mg} \%$ and symptomatic patient

2. The diagnosis of CFRD can be established in a patient who is in an acute exacerbation episode (i.v. antibiotic therapy, systemic corticotherapy) when blood glucose $\geq 126 \mathrm{mg} \%$ or 2 hours post-prandial $\geq 200 \mathrm{mg} \%$ persists for more than 48 hours

3. In enterally-fed patients when in the middle of or at the end of the meal, the blood glucose level exceeds $200 \mathrm{mg} \%$, the diagnosis of CFRD can be established.

4. To diagnose diabetes in a pregnant patient with CF, according to the Study Group of the International Diabetes and Pregnancy Association, the diagnosis is established following the OGTT as follows:

- fasting blood glucose $\geq 92 \mathrm{mg} \%$, or

$-1 \mathrm{~h}$ glucose $\geq 180 \mathrm{mg} \%$, or

- 2 h glucose $\geq 153 \mathrm{mg} \%$.

\section{Treatment}

In order to maintain weight and optimal health status it is advised to maintain a level of glucose within recommended. This is achievable by maintaining a specific nutritional diet, a proper drug treatment and individual physical activity. All patients with CF, including those with diabetes, should follow a hypercaloric diet with $120-150 \%$ of the estimated needs calorie estimated/age and sex [12]. The caloric intake is constituted divided as follows: $35-40 \%$ as fats, $20 \%$ as proteins and $40-45 \%$ as carbohydrates [13], [14], [15].

In patients following multiple injections therapy, the carbohydrates daily intake should be assigned as follows: 3 main meals matching the injections administration schedule. Also, in addition to the meals of the day, it is recommended three snacks consumption to overlap with the maximum action time of the rapid acting insulin.

The hyper-lipidic food consumption during meals, can slow the carbohydrates release by stomach, having an indirect effect on the glucose level [16].

An appropriate diet involves a balanced consumption of all the 6 food groups, insulin doses appropriate for blood glucose level and pancreatic enzymes efficient to support digestion of consumed lipids. It is also recommended to have an individual regular schedule for main meals and snacks every day. There is evidence of weight gain, protein anabolism, pulmonary function improvements and even survival in patients who achieve glycemic control with insulin therapy.

Insulin therapy is currently the only recommended treatment [9]. The anabolic effects of insulin therapy are the most important aspect of treatment, which is why it is recommended to administrate as much insulin as the body can tolerate. The purpose of insulin treatment is to maintain a level of $\mathrm{HbA} 1 \mathrm{c}<7 \%$ [8]. The insulin requirement is low when the patient is in a "normal" state of health. The recommended insulin dose is between $0.5-0.8 \mathrm{u}$.i./kgb/day [17]. During the acute exacerbations, patients may require a greater amount of insulin to reach the target blood glucose level: $70-140 \mathrm{mg} \%$ before meals and $100-180 \mathrm{mg} \%$ post-prandial [8]. In the case of CFRD patients but without fasting hyperglycemia, the insulin administration only as a bolus has a positive effect on weight gain and is currently considered the therapeutic standard [18]. The latest ISPAD recommendations state that for those patients with CFRD but without fasting hyperglycemia who consume moderate amounts of carbohydrates several times a day, only basal insulin can be used [19]. For patients with CFRD and fasting hyperglycemia it is recommended to treat by a combination treatment of both insulin boluses prior to main meals and the use of an insulin pump or long-acting insulin injections [8]. Patients should have a daily glycemic profile, at least 3 times per day, prior to main meals, in order to adjust insulin doses based on the blood glucose level.

Table 3. Treatment protocol [8]

\begin{tabular}{|c|c|}
\hline Basal Insulin & $\begin{array}{l}\text { - INbazal= } 0.25 \mathrm{IU} / \mathrm{kgb} / \mathrm{day} \text {; } \\
\text { It will start with } 1 / 2 \text { the neces- } \\
\text { sary and gradually increase } \\
\text { cosidering the fasting blood } \\
\text { glycemia. }\end{array}$ \\
\hline Bolus Insulin & $\begin{array}{l}\text { - Dstart= } 0.5-1 \text { IU Rapid } \\
\text { acting insulin for every } 15 \mathrm{~g} \\
\text { of consumed carbohydrates } \\
\text { - CFRD patients without } \\
\text { fasting hypoglycaemia can } \\
\text { be treated either with bolus } \\
\text { insuline or with a basal } \\
\text { insulin } \\
\text { - For very young patients } \\
\text { (children who do not con- } \\
\text { sume the whole amount of } \\
\text { food or do not know what } \\
\text { to eat), insulin may also be } \\
\text { administated after a meal, } \\
\text { although it is always better } \\
\text { before. }\end{array}$ \\
\hline $\begin{array}{c}\text { Correction } \\
\text { doses }\end{array}$ & $\begin{array}{l}\text { The patients can adjust bo- } \\
\text { lus insulin doses by } 0.5-1 \\
\text { IU of rapid acting insulin for } \\
\text { each blood glucose level by } \\
50 \mathrm{mg} \% \text { above } 150 \mathrm{mg} \% \text {. }\end{array}$ \\
\hline
\end{tabular}




\section{Treatment monitoring}

In patients with CF and impaired glucose tolerance, it may be advised to avoid concentrated sweets (but not excluding them from diet), the consumption of a constant amount of carbohydrates in main meals and snacks, to prevent hyperglycemic events, and moderate exercise that increases the body's sensitivity to insulin action. All the patients should be trained to recognize, prevent, and treat episodes of hypoglycemia.

The International Society for Pediatric and Adolescent Diabetes (ISPAD) recommends the followings on monitoring CFRD patients [8]:

- After 5 years of diagnosis, annual monitoring of microvascular complications or, if the exact time is unknown, from the time of diagnosis of first hyperglycemia;

- Regular monitoring of blood pressure. For patients with: systolic $\mathrm{BP} \geq 130 \mathrm{mmHg}$ or diastolic $\mathrm{BP} \geq 80 \mathrm{mmHg}$ or $>\mathrm{P} 90$ for age and sex, a new measurement will be made the following day for the purpose of diagnosing HTN

- CFRD patients diagnosed with HBP or microvascular complications will follow the same ADA recommended treatment for all people with diabetes, except that they will not be on a diet with sodium or protein restriction

- CFRD patients with exocrine pancreatic insufficiency will have an annual lipid profile or if they have one of the risk factors: obesity, a familiar history of coronary artery disease or immunosuppressive treatment secondary to a transplant.

\section{Conclusions}

CFRD is an important morbid entity that influences the life quality of CF patients. The major therapeutic goal is to maintain optimal nutritional status in the context of proper glycemic control and prevent the development of long-term complications. Thus, it is advisable to adjust the therapy to the patient's increased caloric needs as well as associated conditions such as pulmonary exacerbations when insulin requirements are increased. The glycemic education and self-control are the key elements in the treatment of CFRD associated with multidisciplinary assessment and monitoring of the patient with cystic fibrosis.

\section{References}

1. Southern KW, Munck A, Pollitt R, Travert G, Zanolla L, Dankert-Roelse J, et al. A survey of newborn screening for cystic fibrosis in Europe. J Cyst Fibros. 2007;6:57-65.

2. Popa I, Pop L, Popa Z, Schwarz MJ, Hambleton G, Malone GM, et al. Cystic fibrosis mutations in Romania. Eur J Pediatr. 1997;156:212-213.

3. O'Sullivan BP, Freedman SD. Cystic fibrosis. Lancet. 2009 May;373(9678):1891904.

4. Ciuca IM, Pop L, Ranetti A., Popescu I.M, et all, Ursodeoxicholic acid effects on cystic fibrosis liver disease, Farmacia, 63: 543547

5. Ciuca IM, Pop LL, Rogobete AF, Onet DI, Guta-Almajan B, Popa Z, et al. Genetic Expression in Cystic Fibrosis Related Bone Disease. An Observational, Transversal, Cross-Sectional Study. Clin Lab. 2016;62(9):1725-30.

6. Marshall BC, Butler SM, Stoddard M, Moran AM, Liou TG, Morgan WJ, et al. Epidemiology of cystic fibrosis-related diabetes. J Pediatr. 2005;146:681-687

7. Moran A, Becker D, Casella SJ, Gottlieb PA, Kirkman MS, Marshall BC, et al. Epidemiology, pathophysiology, and prognostic implications of cystic fibrosis-related diabetes: A technical review. Diabetes Care. 2010;33:2677-2683.

8. Moran A, Pillay K, Becker DJ, Acerini CL. Management of cystic fibrosis-related diabetes in children and adolescents. Pediatr Diabetes. 2014;15:65-76.

9. Moran A, Brunzell C, Cohen RC, Katz M, Marshall BC, Onady G, et al. Clinical care guidelines for cystic fibrosis-related diabetes: A position statement of the American Diabetes Association and a clinical practice guideline of the Cystic Fibrosis Foundation, endorsed by the Pediatric Endocrine Society. Diabetes Care. 2010;33:2697-2708.

10. Lanng S, Hansen A, Thorsteinsson B, Nerup J, Koch C. Glucose tolerance in patients with cystic fibrosis: five year prospective study. BMJ. 1995;311:655-659

11. Brunzell C., Hardin D.S., Kogler A., Moran A., Schindler T. Managing Cystic Fibrosis-Related Diabetets (CFRD) - An Instruction Guide for Patients and Families. Cystic Fibrosis Foundation. 2015; 10.

12. Sinaasappel $M$, Stern $M$, Littlewood J, Wolfe S, Steinkamp G, Heijerman HGM, et al. Nutrition in patients with cystic fibrosis: A European Consensus. Vol. 1, J Cystic Fibros 2002; 1:51-75

13. Engelen MPKJ, Com G, Deutz NEP. Protein is an important but undervalued macronutrient in the nutritional care of patients 
with cystic fibrosis. Vol. 17, Current Opinion in Clinical Nutrition and Metabolic Care, 2014;7:515-520.

14. Gaskin KJ. Nutritional care in children with cystic fibrosis: Are our patients becoming better? Vol. 67, European Journal of Clinical Nutrition, 2013; 67 :558-564

15. Matel JL. Nutritional management of cystic fibrosis. Journal of Parenteral and Enteral Nutrition. 2012; 36: 60S-70S

16. Brunzell C., Hardin D.S., Kogler A., Moran A., Schindler T. Managing Cystic Fibrosis-Related Diabetets (CFRD) - An Instruction Guide for Patients and Families. Cystic Fibrosis Foundation. 2015; 35.

17. Sunni M, Bellin MD, Moran A. Exogenous insulin requirements do not differ between youth and adults with cystic fibrosis related diabetes. Pediatr Diabetes. 2013;14(4):295-298

18. Moran A, Pekow P, Grover P, Zorn M, Slovis $\mathrm{B}$, Pilewski J, et al. Insulin therapy to improve BMI in cystic fibrosis-related diabetes without fasting hyperglycemia: Results of the cystic fibrosis related diabetes therapy trial. Diabetes Care. 2009;32:1783-1788

19. Moran A, Pillay K, Becker D, Granados A, Hameed S, Acerini CL. ISPAD Clinical Practice Consensus Guidelines 2018: Management of cystic fibrosis-related diabetes in children and adolescents. Pediatr Diabetes. 2018;19: 64-74 